\title{
Nonresident parental influence on adolescent weight and weight-related behaviors: similar or different from resident parental influence?
}

\author{
Jerica M Berge ${ }^{1 *}$, Craig Meyer ${ }^{2}$, Richard F MacLehose ${ }^{2}$, Marla E Eisenberg ${ }^{2,3}$ and Dianne Neumark-Sztainer ${ }^{2}$
}

\begin{abstract}
Background: Many parents do not live with, or have shared custody of, their adolescent children (i.e., nonresident parents). The degree of their influence on their children, as compared to parents who do live with their children the majority of the time (i.e. resident parents) has not been well-studied. The current study aimed to examine whether and how resident and nonresident parents' weight and weight-related behaviors are correlated with adolescents' weight and weight-related behaviors. Results will inform who may be important to include in adolescent obesity prevention interventions.

Methods: Data from two linked population-based studies, EAT 2010 and F-EAT, were used for cross-sectional analyses. Resident parents ( $n=200 ; 80 \%$ females; mean age $=41.8$ ), nonresident parents ( $n=200 ; 70 \%$ male; mean age $=43.1$ ), and adolescents ( $n=200 ; 60 \%$ girls; mean age $=14.2$ years) were socioeconomically and racially/ ethnically diverse. Multiple regression models were fit to investigate the association between resident and nonresident parents' weight and weight-related behaviors and adolescents' weight and weight-related behaviors.

Results: Both resident and nonresident parents' BMI were significantly associated with adolescents' BMI percentile. Additionally, resident parents' sugar-sweetened beverage consumption and fruit and vegetable intake were significantly associated with adolescents' sugar-sweetened beverage intake and fruit and vegetable intake $(p<0.05)$, respectively. Furthermore, the association between nonresident parent physical activity and adolescent physical activity was marginally significant $(p=0.067)$. Neither resident nor nonresident parents' fast food consumption, breakfast frequency, or sedentary behaviors were significantly associated with adolescents' same behaviors.

Conclusions: These preliminary findings suggest that resident and nonresident parents may have slightly different influences on their adolescent children's weight-related behaviors. Longitudinal follow-up is needed to determine temporality of associations.
\end{abstract}

Keywords: Resident parent, Nonresident parent, Adolescents, Obesity, Dietary intake, Physical activity

\section{Introduction}

According to national data, it is common for adolescents to live in shared custody arrangements [1]. In fact, $40 \%$ of adolescents from divorced or separated families live in households where custody is equally shared and 50\% live in households where some combination of custody sharing is occurring (only $10 \%$ have no shared custody

\footnotetext{
* Correspondence: jberge@umn.edu

'Department of Family Medicine and Community Health, University of Minnesota Medical School, Phillips Wangensteen Building, 516 Delaware Street SE, Minneapolis, MN 55455, USA

Full list of author information is available at the end of the article
}

arrangements) [1]. Few studies have examined the role of nonresident parents (i.e., child lives with parent $<50 \%$ of the time) in adolescents' weight and weight-related behaviors (e.g., fruit and vegetable intake, physical activity behaviors, dieting) [2]. Understanding whether and how resident (i.e., child lives with parent $\geq 50 \%$ of the time) and nonresident parents' weight and weightrelated behaviors are associated with adolescents' weight and weight-related behaviors will inform researchers regarding which family member(s) may be important to

\section{() Biomed Central}

(c) 2014 Berge et al.; licensee BioMed Central Ltd. This is an Open Access article distributed under the terms of the Creative Commons Attribution License (http://creativecommons.org/licenses/by/4.0), which permits unrestricted use, distribution, and reproduction in any medium, provided the original work is properly credited. The Creative Commons Public Domain Dedication waiver (http://creativecommons.org/publicdomain/zero/1.0/) applies to the data made available in this article, unless otherwise stated. 
include, or focus on, in family-based obesity prevention interventions.

The one study that has examined nonresident parental influence on adolescent eating patterns showed that adolescents in nontraditional households (i.e., single parent homes) ate significantly less healthfully than their counterparts living in dual-headed households [2]. However, adolescents in single-headed households who had nonresident father involvement had more healthful eating patterns than adolescents in single-headed households without nonresident father involvement. Thus, nonresident parents may potentially have a positive influence on adolescent weight-related behaviors.

We are aware of only one study that has examined the differential influence of resident and nonresident parents' influence on adolescent weight and weight-related behaviors (described above) [2]. However, several studies have investigated primary and secondary parent influences within the same home environment in relation to adolescent weight and health behaviors [3-5]. Specifically, parenting style $[4,6,7]$, parent modeling and encouraging of health behaviors [8], conversations about weight and weight-related behaviors [9], parent feeding practices [10-12], and frequency of family meals $[13,14]$ have all been examined to identify risk and protective factors for adolescent obesity risk in the home environment $[3,14]$. Numerous studies have indicated that primary caregivers' (primarily mothers) parenting style $[3,7,15]$, feeding practices $[10,11,13]$ and modeling and encouraging of healthful behaviors $[8,16,17]$ were more strongly associated with adolescents' BMI z-score, dietary patterns, physical activity habits and unhealthy weight control behaviors as compared to secondary parents (primarily fathers), although not all associations have been consistent across studies. A few studies have shown that secondary caregivers' parenting style, feeding practices, modeling and encouraging of healthful behaviors were equally or more strongly associated with adolescents' BMI z-score, dietary patterns, or physical activity habits as compared to the primary caregiver (e.g., father parenting style was significantly associated with more fruit and vegetable intake and lower BMI in daughters) $[4,6]$. Thus, it is important to continue to examine differential parental influences on adolescents' weight and weight-related behaviors and specifically nonresident parental influences since there has been little research conducted with nonresident parents. Additionally, it is important to know for adolescent obesity intervention research whether resident and nonresident parental influence on adolescent weight and weight-related behaviors is similar or different in order to target key people in adolescents' lives that may have the highest likelihood of impacting adolescents' weight-related behaviors.

Thus, given the increased prevalence of adolescent obesity in the last three decades [18], the negative health consequences associated with youth obesity [19], and the frequency of shared custody arrangements of adolescents [1], it is important to know whether and how resident and nonresident parents' weight and weight-related behaviors (i.e., BMI, fruit and vegetable intake, sugarsweetened beverage consumption, breakfast frequency, fast food intake, dieting behavior, physical activity, sedentary behaviors) are associated with their adolescents' weight and weight-related behaviors. The main guiding hypothesis of the study is that resident parents' weight and weight-related behaviors will be more strongly associated with adolescents' weight and weight-related behaviors as compared to nonresident parents' weight and weight-related behaviors.

\section{Methods}

\section{Study design and population}

Data for this analysis were drawn from two coordinated, population-based studies [9]. EAT 2010 (Eating and Activity in Teens) was designed to examine dietary intake, physical activity, weight control behaviors, weight status and factors associated with these outcomes in adolescents. Project F-EAT (Families and Eating and Activity Among Teens) was designed to examine factors within the family and home environment (e.g., parent behaviors, family functioning, home food and physical activity resources) of potential relevance to adolescents' weight and weight-related behaviors [20]. Survey development for both EAT 2010 and F-EAT are described elsewhere. Drafts of the surveys were pre-tested by 56 adolescents and 35 parents from diverse backgrounds for clarity, readability and relevance; and reviewed by an interdisciplinary team of experts. After revisions, the survey was additionally pilot tested with a different sample of 129 middle school and high school students and 102 parents to examine the test-retest reliability of measures over a one-week period. All study procedures were approved by the University of Minnesota's Institutional Review Board Human Subjects Committee and the participating school districts.

For EAT 2010, surveys and anthropometric measures were completed by 2,793 adolescents from 20 public middle schools and high schools in the Minneapolis/St. Paul metropolitan area of Minnesota during the 20092010 academic year. The mean age of the study population was 14.4 years $(\mathrm{SD}=2.0)$ and adolescents were equally divided by gender ( $47 \%$ boys, $53 \%$ girls). The racial/ethnic backgrounds of the participants were as follows: $19 \%$ white, $29 \%$ African American or Black, 20\% Asian American, 17\% Hispanic, 4\% Native American, and $11 \%$ mixed or other. The socioeconomic status (SES) of participants included: 29\% low SES, 24\% lowmiddle SES, 33\% Middle SES, 6\% Upper-Middle SES, and 3\% High SES. 
For Project F-EAT, data were collected by surveying up to two parents/caregivers $(n=3,709)$ of the adolescents in EAT 2010 by mail or phone interviews. In total, 2,382 EAT 2010 (85\%) adolescent participants had at least one parent respond and there were two parent respondents for 1,327 adolescents. Parent participants had a mean age of 42.3 years $(S D=8.6)$. The majority of parent respondents were mothers or other female parents (62\%). Participating parents of adolescents were ethnically and socioeconomically diverse, similar to the adolescent sample.

The study population for the current analysis was restricted to those adolescents $(n=200)$ with two parent respondents, with one parent reporting that their child spent more time living with them (i.e., resident parent; lives with child $\geq 50 \%$ of the time) compared to the other parent (i.e., nonresident parent; lives with child $<50 \%$ of the time). As no gold standard exists in the literature to determine resident vs. nonresident parent status, these cutpoints were established under the premise that a child living with one parent more than the other, at least half of the time, represented resident status. Adolescent participants in this study were predominantly female (60\%), African-American (31\%), with a mean age of 14.2 years. Resident parents were $80 \%$ female, had a mean age of 41.8 years, were $34 \%$ white, and $24 \%$ finished college or more. Nonresident parents were $70 \%$ male, had a mean age of 43.1 years, were 37\% African American, and 19\% finished college or more (See Table 1).

\section{Measures}

BMI

Parent Body Mass Index (BMI) was assessed using parent self-report of height and weight (Test-retest $r=.97$ ). Selfreported height and weight has been shown to be highly correlated with objectively measured values in adults [21]. BMI was calculated using the standard formula, weight (kg)/height (meters) ${ }^{2}$. Adolescent BMI was measured by taking students' heights and weights at school by trained research staff in a private area with standardized equipment and procedures. Adolescents were asked to remove shoes and outerwear (e.g., heavy sweaters). BMI z-scores were calculated according to the following formula: weight $(\mathrm{kg}) /$ height (meters) ${ }^{2}$ and converted to z-scores, standardized for gender and age [22,23].

\section{Dietary intake}

Parent fruit and vegetable intake was assessed by asking parents the following two questions, based on a reliable/ valid measure used in a previous study [24,25], "Thinking back over the past week, how many servings of fruit did you usually eat on a typical day? (A serving is a half cup of fruit or $100 \%$ fruit juice, or a medium piece of fruit)" and "Thinking back over the past week, how many servings of
Table 1 Demographics for adolescents, resident parents (lives with child $\geq \mathbf{5 0} \%$ of the time) and nonresident parents (lives with child $<50 \%$ of the time)

\begin{tabular}{ll}
\hline Adolescent & $\mathbf{2 0 1 0}(\mathbf{n}=\mathbf{2 0 0})$ \\
\hline Female & $60 \%(120)^{*}$ \\
Age & $14.2(1.86)$ \\
White & $23 \%(45)$ \\
African American & $31 \%(61)$ \\
Hispanic & $9 \%(19)$ \\
Asian American & $18 \%(36)$ \\
Hawaiian/Pacific Islander/Other & $19 \%(39)$ \\
Resident parent & \\
Female & $80 \%(160)$ \\
Age & $41.8(8.0)$ \\
Finished college or More (e.g. MD, PhD) & $24 \%(48)$ \\
White & $34 \%(67)$ \\
African American & $31 \%(61)$ \\
Hispanic & $10 \%(19)$ \\
Asian American & $18 \%(35)$ \\
Hawaiian/Pacific Islander/Other & $7 \%(14)$ \\
Non-resident parent & \\
Male & \\
Age (years) & $70 \%(140)$ \\
Finished college or More (e.g. MD, PhD) & $43.1(9.5)$ \\
African American & $19 \%(38)$ \\
Asian American & $28 \%(55)$ \\
\hline Hawaiian/Pacific Islander/Other & $6 \%(74)$ \\
\hline
\end{tabular}

*Values presented as mean (standard deviation) or \% (n).

vegetables did you usually eat on a typical day? (A serving is half a cup of cooked vegetables or one cup of raw vegetables)". For both items there were seven response options ( 0 , $<1,1,2,3,4,5$ or more servings/day) (Test-retest $r=0.69$ [fruit]; $r=0.57$ [vegetables]). Responses for fruit and vegetable intake were coded numerically as $0,0.5,1,2,3,4$, and 5.5, then summed together to create one variable. Parent sugar-sweetened beverage consumption was assessed by asking parents, "Thinking back over the past week, how often did you drink sugar-sweetened beverages (regular soda, pop, Kool-Aid)?" Response options included: less than once per week, 1 drink per week, 2-4 drinks per week, 5-6 drinks per week, 1 per day, or 2 or more per day (Test-retest $=0.66$ ). Responses were coded numerically as $0,1.5,3$, $5.5,7$ and 14, then divided by 7 for daily sugary beverage intake.

Adolescent dietary intake was assessed with the 149item Youth and Adolescent Food Frequency Questionnaire (YAQ) [26]. For fruit and vegetable intake, daily 
servings were defined as the equivalent of one-half cup. A serving of sugar-sweetened beverages (e.g. soda pop, sports drinks) was defined as the equivalent of one glass, bottle, or can. Validity and reliability of the YAQ have been previously tested with youth and found to be within acceptable ranges for dietary assessment tools $[26,27]$. Responses to questions on the frequency of intake of fruits $(\mathrm{n}=14$; excluding fruit juice) and vegetables $(n=20$; excluding french fries), were summed to assess average total daily intake.

\section{Fast food intake}

Parent and adolescent fast food intake was assessed by asking: "In the past week, how often did you eat something from a fast food restaurant, such as McDonald's, Burger King, Domino's or similar places (pizza counts)?" There were six response options: $0,1-2,3-4,5-6,7$ or more than 7 times/week (Test-retest $\mathrm{r}=0.55$ [parent]; $\mathrm{r}=0.38$ [adolescent]). Responses were coded numerically as $0,1.5,3.5,5.5,7$ and 9 .

\section{Dieting}

Parent and adolescent dieting was assessed by selfreport using the following question, "How often have you gone on a diet during the last year? By 'diet' we mean changing the way you eat so you can lose weight." [28] Responses included: never, one to four times, five to 10 times, more than 10 times, and I am always dieting (Test-retest $=0.60$ [parent]; $r=0.65$ [adolescent]). To distinguish dieters from non-dieters, responses were dichotomized into no (never) and yes (other responses). Sensitivity analyses indicated that collapsing the dieting variable produced similar results as the original 5 -item scale.

\section{Physical activity}

Parent and adolescent physical activity questions were adapted from the Godin Leisure-Time Exercise Questionnaire [29]. parents and adolescents were asked: "In a usual week, how many hours do you spend doing the following activities: (1) strenuous exercise (e.g. biking fast, aerobics, jogging, basketball, swimming laps, soccer, rollerblading) (2) moderate exercise (e.g. walking quickly, easy bicycling, volleyball, skiing, dancing, skateboarding, snowboarding)." Response options ranged from "none" to " $6+$ hours a week". (Test-retest $r=0.75$ [parent]; $r=0.72$ [adolescent]). Items were summed together to assess average hours of moderate and vigorous physical activity per week.

\section{Sedentary behavior}

Parent and adolescent sedentary behavior was assessed by asking parents, "In your free time on an average weekday (Monday-Friday), how many hours do you spend doing the following activities?...[0 hr, $1 / 2 \mathrm{hr}, 1 \mathrm{hr}$,
$2 \mathrm{hr}, 3 \mathrm{hr}, 4 \mathrm{hr}, 5+\mathrm{hr}$." [30] The activities assessed included: Watching TV/DVDs/videos, Using a computer (not for homework), and Xbox/Play-Station/other electronic games that you play when sitting. This same question was asked for weekends. For each sedentary behavior an "hours per week" variable was created by multiplying the weekday hours per day by 5 and adding it to the weekend hours per day multiplied by 2 . Students who reported $5+$ hours of use were coded as having 6 hours. Total sedentary behavior per week was calculated as the sum of the three individual behaviors per week (Test-retest $r=0.78$ [parent]; $\mathrm{r}=0.86$ [adolescent]).

\section{Control variables}

Race/ethnicity, educational attainment, and age were assessed by self-report. Parent and adolescent race/ethnicity was assessed with one survey item: 'Do you think of yourself as 1) white, 2) black or African-American, 3) Hispanic or Latino, 4) Asian-American, 5) Hawaiian or Pacific Islander, or 6) American Indian or Native American' and respondents were asked to check all that apply. Participants who checked 'white' and another option were included in the other category. Those who checked two non-white options were categorized as 'mixed/other race'. Additionally, those checking Hawaiian/Pacific Islander or Native American were also categorized as 'mixed/other race' due to their small numbers in this dataset. Parent educational attainment was assessed using the following question, "What is the highest level of education that you have completed?" Response options included: less than high school, high school/GED, vocational/technical/trade school, associate degree, bachelor degree, graduate or professional degree. Parent and adolescent age was calculated using self-reported birth date and survey completion date.

\section{Statistical analysis}

Descriptive statistics for study variables included means and standard deviations for continuous variables and frequencies and percentages for categorical variables. To compare differences between resident parent and nonresident parent variables, $\mathrm{t}$-tests were conducted for continuous variables including BMI, hours of weekly physical and sedentary activity, daily servings of fruits and vegetables, weekly frequency of fast food consumption, daily consumption of sugary beverages, weekly frequency of eating breakfast, and a Chi-square test for the binary variable dieting.

Continuous dependent variables (adolescent BMI zscores, weekly hours of physical activity, weekly hours of sedentary activity, daily servings of fruits and vegetables, weekly frequency of fast food consumption, daily consumption of sugary beverages, and weekly frequency of eating breakfast) were modelled using separate linear regressions. The corresponding independent variables for 
both resident and nonresident parents were included in each model. Because parent BMI was measured differently from adolescent BMI (i.e., adolescent $=$ BMI z-score), adolescent BMI z-score was estimated for a 1-unit change in parent BMI $\left(\mathrm{kg} / \mathrm{m}^{2}\right)$. Adolescent dieting, a dichotomous variable, was modeled using logistic regression with the corresponding dieting variables of both resident and nonresident parents. Adjusted probabilities of adolescent dieting were computed from the logistic regression for each level of dieting (yes/no) for both resident and nonresident parents. These adjusted probabilities were used to calculate risk differences and corresponding standard errors were estimated by Taylor-series expansion. F-tests were used to compare differences between resident and nonresident parent regression coefficients of independent variables.

To determine if there were differences in effects between the resident and nonresident parents' independent variables and adolescent gender, tests of interactions were conducted by including interaction terms in all models. Statistically significant differences by adolescent gender were not found for both resident and nonresident independent variables, and main effects are reported only. All final models were adjusted for adolescent gender and race/ethnicity and resident and non-resident parent gender and educational attainment.

\section{Results}

Descriptive results showed that nonresident and resident parents engaged in similar amounts of healthful and unhealthful behaviors including: weekly hours of sedentary behavior, fruit and vegetable intake, sugar-sweetened beverage intake, frequency of eating breakfast, and the proportion of parents engaging in dieting behaviors (Table 2). In addition, resident and nonresident parents had similar BMI values. The only health behavior for which resident and nonresident parents significantly differed was fast food intake, with nonresident parents consuming significantly more fast food per week ( $\mathrm{p}=0.002$; Table 2). Additionally, nonresident parents' physical activity levels (5.5 hours/ week) were slightly higher than resident parents' physical activity levels, although this finding was marginally significant (4.6 hours/week; $\mathrm{p}=0.052$ ).

\section{Associations between resident and nonresident parents' weight and weight-related behaviors and adolescents' weight and weight-related behaviors}

Both resident and nonresident parents' BMI were associated with adolescents' BMI $\mathrm{z}$-score ( $\mathrm{p}<0.001$; Table 3$)$. Additionally, resident parents' sugar-sweetened beverage consumption was associated with adolescent sugarsweetened beverage consumption $(\mathrm{p}=0.001)$. Furthermore, resident parents' fruit and vegetable intake was associated with adolescent fruit and vegetable intake $(p=0.048)$. However, resident parents' fast food consumption, breakfast frequency, physical activity, sedentary behavior and dieting were not significantly associated with adolescents' same behaviors.

Nonresident parents' physical activity was marginally associated with adolescent physical activity $(\mathrm{p}=0.067)$. However, nonresident parents' fruit and vegetable intake, sugar-sweetened beverage consumption, breakfast frequency, fast food intake, sedentary behavior, and dieting were not significantly associated with adolescents' same behaviors.

Although there were significant associations between resident parents' weight, sugar-sweetened beverage consumption, and fruit and vegetable intake and adolescents' weight, sugar-sweetened beverage consumption and fruit and vegetable intake, these associations did not significantly differ between resident and nonresident parents. For example, the beta estimate of 0.33 representing the association between resident parent's sugar-sweetened beverage consumption and adolescent's sugar-sweetened beverage consumption was not significantly different from the beta estimate of 0.04 representing the association

Table 2 Paired $t$-test and chi-squared comparisons between resident and nonresident parents' BMI, physical activity and eating behaviors*

\begin{tabular}{lllll}
\hline & $\mathbf{N}^{* *}$ & Resident parent & Non-resident parent & p-value \\
\hline BMI $\frac{\mathbf{k g}}{\left(\mathbf{m}^{2}\right)}$ & 185 & $27.3(26.5,28.1)^{* * *}$ & $27.7(27.0,28.5)$ & 0.39 \\
Physical activity (hrs/wk) & 198 & $4.6(4.0,5.2)$ & $5.5(4.8,6.1)$ & 0.05 \\
Sedentary activity (hrs/wk) & 197 & $15.4(13.8,17.0)$ & $16.3(14.8,17.7)$ & 0.31 \\
Fruits \& Vegetables (servings/day) & 199 & $3.5(3.2,3.8)$ & $3.2(2.9,3.5)$ & 0.19 \\
Fast food consumption (\# times/wk) & 200 & $1.5(1.3,1.7)$ & $2.0(1.7,2.2)$ & 0.00 \\
Sugary beverages (\#/day) & 200 & $0.6(0.5,0.7)$ & $0.7(0.6,0.8)$ & 0.10 \\
Breakfast (\#/wk) & 199 & $4.4(4.0,4.8)$ & $4.0(3.7,4.4)$ & 0.11 \\
Dieting (Proportion) & 198 & $0.5(0.4,0.5)$ & $0.4(0.4,0.5)$ & 0.14 \\
\hline
\end{tabular}

*Resident parent $=$ lives with child $\geq 50 \%$ of the time; Nonresident parent $=$ lives with child $<50 \%$ of the time

${ }^{*} \mathrm{~N}$ represents total in paired $t$-test comparisons.

***Values presented as Mean $(95 \% \mathrm{Cl})$; Bolded $\mathrm{p}$-value represent statistically significant difference between resident and nonresident parent's behavior at $\mathrm{p}<0.05$. 
Table 3 Association between adolescent BMI percentile, physical activity and eating behaviors and resident* and nonresident parents' BMI, physical activity and eating behaviors**

\begin{tabular}{|c|c|c|c|}
\hline & $\mathrm{N}^{* * *}$ & Resident parent ${ }^{* * * *}$ & Non-resident parent \\
\hline BMI (z-score) & 185 & $0.04(0.02,0.07)^{\mathrm{A}^{* * * * *}}$ & $0.06(0.04,0.09)^{A}$ \\
\hline Physical activity (hrs/wk) & 198 & $0.11(-0.06,0.27)^{\mathrm{A}}$ & $0.13(-0.01,0.27)^{\mathrm{A}}$ \\
\hline Sedentary activity (hrs/wk) & 197 & $-0.13(-0.48,0.22)^{\mathrm{A}}$ & $0.01(-0.36,0.38)^{\mathrm{A}}$ \\
\hline Fruits \& Vegetables (servings/day) & 188 & $0.14(0.00,0.29)^{A}$ & $0.06(-0.09,0.21)^{\mathrm{A}}$ \\
\hline Fast food consumption (\# times/wk) & 199 & $0.05(-0.10,0.20)^{\mathrm{A}}$ & $-0.01(-0.13,0.11)^{\mathrm{A}}$ \\
\hline Sugary beverages (\#/day) & 191 & $0.33(0.13,0.54)^{A}$ & $0.04(-0.16,0.24)^{\mathrm{A}}$ \\
\hline Breakfast (\#/wk) & 199 & $0.09(-0.07,0.24)^{\mathrm{A}}$ & $0.02(-0.13,0.17)^{\mathrm{A}}$ \\
\hline Dieting (Risk difference) & 197 & $0.02(-0.12,0.15)^{\mathrm{A}}$ & $-0.02(-0.16,0.12)^{\mathrm{A}}$ \\
\hline
\end{tabular}

*Resident parent $=$ lives with child $\geq 50 \%$ of the time; Nonresident parent $=$ lives with child $<50 \%$ of the time

**Models adjusted for child's gender, race/ethnicity, and resident and non-resident parent's gender and educational attainment.

${ }^{* * *} \mathrm{~N}$ represents total in final model without missing information on outcome, exposure, and confounders.

****Values presented as $\beta(95 \% \mathrm{Cl})=$ expected change in means for continuous variables and proportions for dieting of the adolescent for a 1 unit increase in parents' variable and 95\% confidence interval; bolded if $\mathrm{p}<0.05$.

*****Coefficients not sharing a letter are statistically significant at $a=0.05$

between nonresident parent's sugar-sweetened beverage consumption and adolescent's sugar-sweetened beverage consumption.

\section{Discussion}

Results from the current study both reinforce findings from previous studies and expand findings from prior research. The finding that both resident and nonresident parents' BMI were significantly associated with adolescents' BMI z-score corroborates previous research [31-33] that lends support to the hypothesis that weight status and obesity are correlated within family, due to both genetic and environmental factors.

Additionally, the findings that resident parents' fruit and vegetable intake and sugar-sweetened beverage consumption (but not other weight-related behaviors such as fast food intake, breakfast frequency, dieting, physical activity and sedentary behavior) were associated with similar behaviors in their adolescent children both corroborate and expand upon earlier findings regarding primary caregiver's influence on adolescents' weight-related behaviors [4,34]. Specifically, previous studies have found mixed results regarding associations between primary parents' modeling of fast food consumption, fruit and vegetable intake, sugar-sweetened beverage consumption, dieting behaviors, physical activity and sedentary behaviors and adolescents' same behaviors [33,35-38]. The current study expands previous research suggesting that resident parents', but not nonresident parents', fruit and vegetable intake and sugarsweetened beverage consumption, may influence adolescents' likelihood of engaging in the same behaviors. One potential implication of these findings, although results are not consistent across all adolescent weight-related behaviors, is that interventions may be able to solely target resident parents' fruit and vegetable intake and sugarsweetened beverage consumption in order to influence adolescents' engaging in these key behaviors that have been strongly linked to obesity, weight gain (sugar-sweetened beverage intake) [39] or weight loss/maintenance overtime (fruit and vegetable intake) [28]. For example, adolescent obesity prevention interventions may want to focus on emphasizing resident parent modeling of healthful eating behaviors and parenting practices, above and beyond nonresident parent eating behaviors.

Additionally, nonresident parent's physical activity was marginally associated with adolescent's physical activity and thus may be a potential influence on adolescents engaging in physical activity themselves. This is an interesting finding that needs to be replicated in future research, due to the marginal significance of the finding. It may be important to consider intervening on resident parent's influence on adolescent's dietary intake and nonresident parent's influence on adolescent's physical activity in adolescent obesity interventions. One potential hypothesis for this finding is that when children visit their nonresident parent they may spend more time being active together, thus providing an opportunity for the nonresident parent to model physical activity and in turn, increase the likelihood that the adolescent will be more physically active overall. Future research is needed to understand this finding, such as qualitative research that can explore reasons why this association may exist.

Study strengths and limitations should be taken into account when interpreting the study findings. The current study had several strengths. This analysis was connected to a data set that includes a large, diverse, populationbased sample with a high response rate, allowing for more confidence in generalization of findings to similar populations. In addition, independent reports were collected from resident parents, nonresident parents and adolescent themselves, which is not commonly done. Furthermore, several weight-related behaviors were measured (e.g., fruit 
and vegetable intake, breakfast frequency, sugar-sweetened beverage intake, fast food consumption, physical activity, sedentary behavior, dieting) and adjustments were made for possible third variable confounding of results (age, parent education, race/ethnicity, parent BMI). Although information was collected on a large number of adolescents, the number of adolescents in the current study was limited to much smaller subset of the overall population. This reduced size resulted in larger standard errors and less precise associations. Furthermore, this study was cross-sectional. Because we were unable to examine longitudinal associations, we cannot establish temporality of associations. For example, it may be the case that adolescents' weight and weight-related behaviors influence parents' weight and weight-related behaviors rather than parents' being more influential. Most likely, the influence is bi-directional and it is important for future studies to use mixed-methods studies to identify parent and adolescent opinions about the bi-directional influential patterns around weight and weight-related behaviors that may be occurring in the home environment. In addition, longitudinal studies are needed to examine bi-directional influences of weight and weight-related behaviors. Furthermore, all survey measures were self-report measures and may have been prone to social desirable responses from both parent and adolescent participants.

\section{Conclusions}

Resident parents' BMI, fruit and vegetable intake and sugar-sweetened beverage consumption was significantly associated with similar behaviors in their adolescent children, however only nonresident parents' BMI and physical activity (marginal) was associated with adolescents' BMI and physical activity. Thus, future research is needed to further explore the association between resident and nonresident parent weight and weight-related behaviors and adolescents' weight and weight-related behaviors. Additionally, it would be important for future research to examine resident and nonresident parental influences on younger children's weight and weight-related behaviors, who may be more dependent on their caregivers' modeling of weight and weight-related behaviors in the home environment. Furthermore, it may be useful for healthcare providers to ask adolescents about both resident and nonresident parents' eating and physical activity behaviors, how they spend time with each parent, and suit recommendations to individual adolescent-parent pair.

\section{Competing interests}

The authors declare that they have no competing interests.

\section{Authors' contributions}

All co-authors made a substantial contribution to the paper. JMB and RFM are the co-principal investigators on the grant. JMB conceptualized the paper, assisted with data analysis and interpretation, and wrote all drafts of the paper. RFM assisted with the conceptualization of the paper, the study design and the data analysis. He also critically reviewed the paper and gave final approval of the version to be published. CM conducted the data analysis. He also critically reviewed the paper and gave final approval of the version to be published. MEE assisted with interpretation of study results, critically reviewed the manuscript, and gave final approval of the version to be published. DNS assisted in conceptualizing the paper and contributed to the design of the study. She also critically reviewed the paper and gave final approval of the version to be published. All authors read and approved the final manuscript.

\section{Acknowledgements}

Research is supported by grant number R03 HD074677 from the National Institute of Child Health and Human Development (CO-PI's: Berge and MacLehose), R01 HL093247 (PI: Neumark-Sztainer) and R01 HL084064 from the National Heart, Lung, and Blood Institute (PI: Neumark-Sztainer). The content is solely the responsibility of the authors and does not necessarily represent the official views of the National Heart, Lung and Blood Institute, the National Institute of Child Health and Human Development, the National Cancer Institute or the National Institutes of Health.

\section{Author details}

${ }^{1}$ Department of Family Medicine and Community Health, University of Minnesota Medical School, Phillips Wangensteen Building, 516 Delaware Street SE, Minneapolis, MN 55455, USA. ${ }^{2}$ Division of Epidemiology and Community Health, University of Minnesota, Phillips Wangensteen Building, 516 Delaware Street SE, Minneapolis, MN 55455, USA. ${ }^{3}$ Division of Adolescent Health and Medicine, University of Minnesota, Phillips Wangensteen Building, 516 Delaware Street SE, Minneapolis, MN 55455, USA.

Received: 22 May 2014 Accepted: 10 October 2014 2.

\section{References}

1. Children Living Arrangements 2012. http://www.census.gov/hhes/families/ data/cps2012C.html. Accessed 12/10/13.

2. Stewart $S$, Menning C: Family structure, nonresident father involvement and adolescent eating patterns. J Adolesc Health 2009, 45:193-201.

3. Berge JM: A review of familial correlates of child and adolescent obesity: what has the 21st century taught us so far? Int I Adolesc Med Health 2009, 21(4):457-483.

4. Berge J, Wall M, Bauer K, Neumark-Sztainer D: Parenting characteristics in the home environment and adolescent overweight. Obesity 2009, 17:1-8

5. Birch LL, Ventura AK: Preventing childhood obesity: what works? Int J Obes (Lond) 2009, 33(Suppl 1):S74-S81.

6. Berge JM, Wall M, Loth K, Neumark-Sztainer D: Parenting style as a predictor of adolescent weight and weight-related behaviors. J Adolesc Health 2010, 46(4):331-338.

7. Rhee KE, Lumeng JC, Appugliese DP, Kaciroti N, Bradley RH: Parenting styles and overweight status in first grade. Pediatrics 2006, 117:2047-2054

8. Berge JM, Wall M, Bauer KW, Neumark-Sztainer D: Parenting characteristics in the home environment and adolescent overweight: a latent class analysis. Obesity (Silver Spring, Md) 2010, 18(4):818-825.

9. Berge JM, Maclehose R, Loth KA, Eisenberg M, Bucchianeri MM, Neumark-Sztainer D: Parent conversations about healthful eating and weight: associations with adolescent disordered eating behaviors. JAMA Pediatr 2013, 167(8):746-753.

10. Birch LL, Fisher JO: Mothers' child-feeding practices influence daughters' eating and weight. Am J Clin Nutr 2000, 71:1054-1061.

11. Birch LL, Fisher JO, Davison KK: Learning to overeat: maternal use of restrictive feeding practices to promote girls' eating in the absence of hunger. Am J Clin Nutr 2003, 78:215-220.

12. Birch $L L$, Davison KK: Family environmental factors influencing the developing behavioral controls of food intake and childhood overweight. Pediatr Clin North Am 2001, 48:893-907.

13. Berge JM, Wall M, Neumark-Sztainer D, Larson N, Story M: Parenting style and family meals: cross-sectional and 5-year longitudinal associations. J Am Diet Assoc 2010, 110(7):1036-1042.

14. Fulkerson JA, Neumark-Sztainer D, Hannan PJ, Story M: Family meal frequency and weight status among adolescents: cross-sectional and five-year longitudinal associations. Obesity 2008, 16(11):2529-2534. 
15. Berge JM, Wall M, Larson N, Eisenberg ME, Loth KA, Neumark-Sztainer D: The unique and additive associations of family functioning and parenting practices with disordered eating behaviors in diverse adolescents. J Behav Med 2014, 37:205-217.

16. Neumark-Sztainer D, Story M, Hannan PJ, Tharp T, Rex J: Factors associated with changes in physical activity: a cohort study of inactive adolescent girls. Arch Pediatr Adolesc Med 2003, 157:803-810.

17. Neumark-Sztainer D, Maclehose R, Loth K, Fulkerson JA, Eisenberg ME, Berge J: What's for dinner? Types of food served at family dinner differ across parent and family characteristics. Public Health Nutr 2012, 19:1-11.

18. Ogden $\mathrm{CL}$, Carroll MD, Kit BK, Flegal KM: Prevalence of obesity and trends in body mass index among US children and adolescents, 1999-2010. JAMA 2012, 307(5):483-490.

19. Daniels SR: Complications of obesity in children and adolescents. Int J Obes (Lond) 2009, 33(Suppl 1):S60-S65.

20. Berge JM, MacLehose RF, Loth K, Eisenberg ME, Fulkerson J, Neumark-Sztainer D: Family meals: Associations with weight and eating behaviors among mothers and fathers. Appetite 2012, 58:1128-1135.

21. Stewart A: The reliability and validity of self-reported weight and height. J Chronic Dis 1982, 35:295-309.

22. Kuczmarski RJ, Ogden CL, Grummer-Strawn LM, Flegal KM, Guo SS, Wei R, Mei Z, Curtin LR, Roche AF, Johnson CL: 2000 CDC growth charts for the United States: methods and development. Vital Health Stat 2002, Series 11(246):1-190

23. Himes $J H$, Dietz WH: Guidelines for overweight in adolescent preventive services: recommendations from an expert committee. The expert committee on clinical guidelines for overweight in adolescent preventive services. Am J Clin Nutr 1994, 59(2):307-316.

24. Hanson NI, Neumark-Sztainer D, Eisenberg ME, Story M, Wall M: Associations between parental report of the home food environment and adolescent intakes of fruits, vegetables, and dairy foods. Public Health Nutr 2005, 8:77-85.

25. Boutelle KN, Birkeland RW, Hannan PJ, Story M, Neumark-Sztainer D: Associations between maternal concern for healthy eating and maternal eating behaviors, home food availability, and adolescent eating behaviors. J Nutr Educ Behav 2007, 39:248-256.

26. Rockett H, Breitenbach M, Frazier A, Wischi J, Wolf A, Field A, Colditz G: Validation of a youth/adolescent food frequency questionnaire. Prev Med 1997, 26(6):808-816.

27. Rockett HR, Wolf AM, Colditz GA: Development and reproducibility of a food frequency questionnaire to assess diets of older children and adolescents. J Am Diet Assoc 1995, 95(3):336-340.

28. Neumark-Sztainer D, Wall MM, Hannan PJ, Story M, Croll J, Perry C: Correlates of fruit and vegetable intake among adolescents: findings from project EAT. Prev Med 2003, 37(3):198-208.

29. Van Cleave J, Gortmaker SL, Perrin JM: Dynamics of obesity and chronic health conditions among children and youth. J Am Med Assoc 2010, 303(7):623-630.

30. Godin G: Godin leisure-time exercise questionnaire. Med Sci Sports Exerc 1997, 29(Suppl 6):S36-S38.

31. Guillaume M, Lapidus L, Beckers F, Lambert A, Bjorntorp P: Familial Trends of Obesity Through Three Generations: The Belgian-Luxembourg Child Study. 1995.

32. Berge JM, Saelens BE: Familial influences on adolescents' eating and physical activity behaviors. Adolesc Med State Art Rev 2012, 23(3):424-439.

33. Strober M, Humphrey LL: Familial contributions to the etiology and course of anorexia nervosa. J Consult Clin Psychol 1987, 55(5):654-659.

34. Raynor HA, Jelalian E, Vivier PM, Hart CN, Wing RR: Parent-reported eating and leisure-time activity selection patterns related to energy balance in preschool- and school-aged children. J Nutr Educ Behav 2009, 41(1):19-26.

35. Kalakanis LE, Goldfield GS, Paluch RA, Epstein LH: Parental activity as a determinant of activity level and patterns of activity in obese children. Res Q Exerc Sport 2001, 72(3):202-209.

36. Savage JS, Fisher JO, Birch LL: Parental influence on eating behavior: conception to adolescence. J Law Med Ethics 2007, 35(1):22-34.

37. Barradas DT, Fulton JE, Blanck HM, Huhman M: Parental influences on youth television viewing. J Pediatr 2007, 151(4):369-373.
38. McGuire MT, Hannan PJ, Neumark-Sztainer D, Falkner Crossrow NH, Story M: Parental correlates of physical activity in a racially/ethnically diverse adolescent sample. J Adolesc Health 2002, 30:253-261.

39. Hu FB: Resolved: there is sufficient scientific evidence that decreasing sugar-sweetened beverage consumption will reduce the prevalence of obesity and obesity-related diseases. Obes $\operatorname{Rev} 2013,14(8): 606-619$

doi:10.1186/s12966-014-0131-y

Cite this article as: Berge et al:: Nonresident parental influence on adolescent weight and weight-related behaviors: similar or different from resident parental influence? International Journal of Behavioral Nutrition and Physical Activity 2014 11:131.

\section{Submit your next manuscript to BioMed Central and take full advantage of:}

- Convenient online submission

- Thorough peer review

- No space constraints or color figure charges

- Immediate publication on acceptance

- Inclusion in PubMed, CAS, Scopus and Google Scholar

- Research which is freely available for redistribution

Submit your manuscript at www.biomedcentral.com/submit
C) Biomed Central 